\title{
Quiz
}

\section{Hinein in hypoxische Zonen}

Man stelle sich vor, es gebe einen Nanocarrier, der therapeutische Substanzen direkt in die hypoxischen Tumorzonen manövriert. Das klingt fast zu schön um wahr zu sein. Aber Ouajdi Felfoul und Kollegen vom NanoRobotics Laboratory der Polytechnique Montreal scheinen in einem Bakterium einen geeigneten Kandidaten gefunden zu haben [Felfoul $\mathrm{O}$ et al. Nat Nanotechnol. 2016;11(11):941-7]. Der Schlüssel lautet Magneto-Aerotaxis. Die Bakterien schwimmen entlang magnetischer Feldlinien und in Richtung geringerer Sauerstoffkonzentration. Das bedeutet, man kann sie mithilfe eines computergenerierten magnetischen Feldes zum Tumor führen und dann dringen sie aufgrund ihrer aerotaktischen Eigenschaften quasi von alleine in hypoxische Zonen vor. Dass sie auch mit Nanoliposomen beladen ihren Weg finden, haben die Forscher im Tierexperiment mit immundefizienten Mäusen bereits unter Beweis gestellt. Kim Jené

Welches besondere Bakterium wurde in der Untersuchung verwendet?

A Magnetospirillum magnetotacticum

B Magnetococcus marinus

C Magnetobacterium bavaricum

Der Buchstabe der richtigen Antwort ist

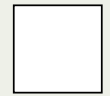

Name

Straße, Nr.

PLZ, Ort

Was ich noch sagen wollte ...

Coupon bitte ausfüllen und abschicken an

Springer Medizin Verlag $\mathrm{GmbH}$

Redaktion Im Focus Onkologie - Quiz 12/2016

Aschauer Straße 30, 81549 München

Oder senden Sie uns eine E-Mail an doris.berger@springer.com

Einsendeschluss: 20.02.2017

\section{Und das können} Sie gewinnen ...

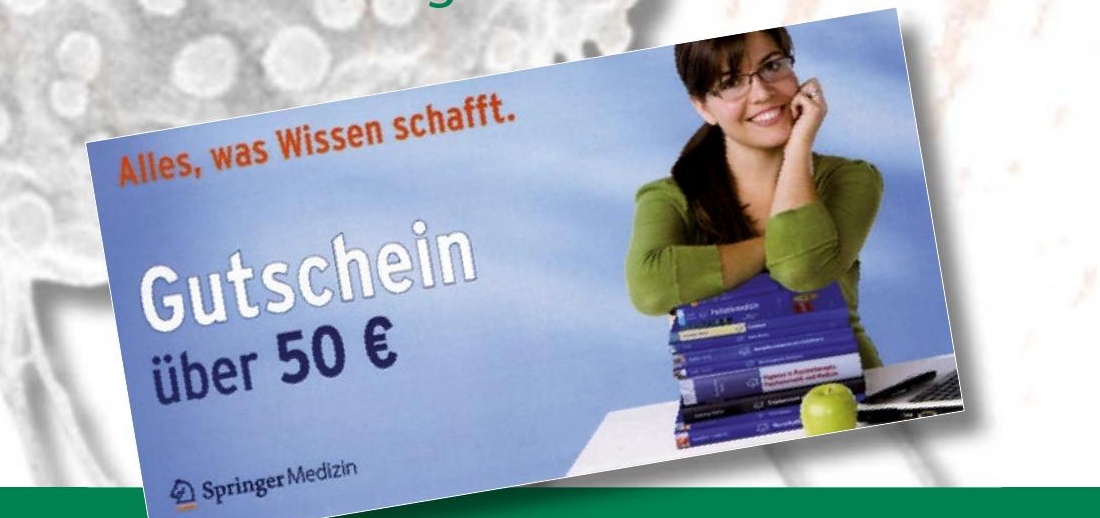

Q SpringerMedizin
Lösung des Quiz 10/2016 Richtig war: $\mathrm{C}$

Unter den richtigen Einsendungen verlosen wir drei Gutscheine über 50 Euro, die Sie für ein beliebiges Springer-Buch einlösen können.
Der Gewinn geht an: R. Thiele, Halle/Saale

Herzlichen Glückwunsch! 